\title{
Analyst
}

Check for updates

Cite this: Analyst, 2021, 146, 222

Received 20th June 2019,

Accepted 9th October 2020

DOI: 10.1039/c9an01134j

rsc.li/analyst

\section{Detection and quantification of exhaled volatile organic compounds in mechanically ventilated patients - comparison of two sampling methods $\uparrow$}

\author{
Pouline M. P. van Oort, $\star^{\mathrm{a}}$ lain R. White, ${ }^{\star b, c}$ Waqar Ahmed, ${ }^{\mathrm{b}, \mathrm{d}}$ Craig Johnson, ${ }^{\mathrm{b}}$ \\ Jonathan Bannard-Smith, ${ }^{\text {e }}$ Timothy Felton, ${ }^{\text {ed }}$ Lieuwe D. Bos, ${ }^{a}$ \\ Royston Goodacre, (D) ${ }^{f}$ Paul Dark ${ }^{e, d}$ and Stephen J. Fowler (D) e,d
}

\begin{abstract}
Exhaled breath analysis is a promising new diagnostic tool, but currently no standardised method for sampling is available in mechanically ventilated patients. We compared two breath sampling methods, first using an artificial ventilator circuit, then in "real life" in mechanically ventilated patients on the intensive care unit. In the laboratory circuit, a 24-component synthetic-breath volatile organic compound (VOC) mixture was injected into the system as air was sampled: (A) through a port on the exhalation limb of the circuit and (B) through a closed endo-bronchial suction catheter. Sorbent tubes were used to collect samples for analysis by thermal desorption-gas chromatography-mass spectrometry. Realistic mechanical ventilation rates and breath pressure-volume loops were established and method detection limits (MDLs) were calculated for all VOCs. Higher yields of VOCs were retrieved using the closed suction catheter; however, for several VOCS MDLs were compromised due to the background signal associated with plastic and rubber components in the catheters. Different brands of suction catheter were compared. Exhaled VOC data from 40 patient samples collected at two sites were then used to calculate the proportion of data analysed above the MDL. The relative performance of the two methods differed depending on the VOC under study and both methods showed sensitivity towards different exhaled VOCs. Furthermore, method performance differed depending on recruitment site, as the centres were equipped with different brands of respiratory equipment, an important consideration for the design of multicentre studies investigating exhaled VOCs in mechanically ventilated patients.
\end{abstract}

\section{Introduction}

Hundreds of volatile organic compounds (VOCs) are present in human breath, ${ }^{1}$ either produced by the host through metabolic processes in health and disease, and/or after ingestion

\footnotetext{
${ }^{a}$ Department of Intensive Care, Amsterdam UMC - location Academic Medical Centre (AMC), Amsterdam, the Netherlands

${ }^{b}$ Manchester Institute of Biotechnology, University of Manchester, Manchester, UK ${ }^{c}$ Laboratory for Environmental and Life Sciences, University of Nova Gorica, Nova Gorica, Slovenia

${ }^{d}$ Division of Infection, Immunity and Respiratory Medicine, School of Biological Sciences, Faculty of Biology, Medicine and Health, and NIHR Manchester Biomedical Research Centre, University of Manchester, Manchester, UK

${ }^{e}$ Manchester Academic Health Science Centre, Manchester University Hospitals NHS Foundation Trust, Manchester, UK. E-mail: stephen.fowler@manchester.ac.uk ${ }^{f}$ Department of Biochemistry, Institute of Integrative Biology, University of Liverpool, $U K$

$\dagger$ Iain White was involved in the execution of the experiments and in writing the initial manuscript, but he is unaware of the final manuscript as we are unable to contact him. Therefore he does not take responsibility for its contents.

$\$$ Both authors contributed equally.
}

(e.g. food, medications), ${ }^{2}$ microbiota $^{3}$ or the environment. ${ }^{4}$ Exhaled breath analysis has shown widespread diagnostic potential in infectious and inflammatory lung diseases, for example in COPD, asthma, cystic fibrosis, tuberculosis and pneumonia. $^{5-9}$ In mechanically ventilated patients on the intensive care unit (ICU), exhaled breath analysis has shown potential for diagnosing diseases including acute respiratory distress syndrome (ARDS) ${ }^{10}$ and ventilator-associated lower respiratory tract infections (VA-LRTIs), ${ }^{11-13}$ with the added advantage that it is non-invasive and does not cause any stress to the patient.

Gas chromatography-mass spectrometry (GC-MS) is the current gold standard for detection and identification of exhaled VOCs. ${ }^{3}$ GC-MS is not suitable for the bedside and so several breath sampling methods have been investigated to enable capture and transportation of samples off-site. Previous studies reported the use of glass syringes and gas sampling bags. ${ }^{14-16}$ Although they are low cost and have been used to capture breath gas in many studies, they are associated with loss of metabolites and sample contamination for example di- 
methylacetamide, phenol, 2-methyl-1,3-dioxalane. ${ }^{17-19}$ Stainless steel tubes filled with sorbent material pre-concentrate the breath sample and are suitable for transportation and storage with minimal loss of VOCs. ${ }^{20}$ Needle trap devices have also been used to trap VOCs. ${ }^{21,22}$ Currently there is no consensus regarding the ideal method for bedside breath sampling and transport although the need to develop a strategy to achieve this is widely accepted. ${ }^{23}$

Standardization of VOC sampling methods in mechanically ventilated patients remains challenging and is contingent on fully defining sampling systems in terms of their analytical performance, including dynamic range, detection limit, noise and the sensitivity of matrix effects towards ambient changes. Previously, two methods of VOC capture using different sampling sites within the ventilator circuit have shown to be safe and feasible: a semi-invasive method using a closed endobronchial suction catheter, ${ }^{11}$ and a completely non-invasive technique whereby samples are diverted through a port on the exhalation limb of the ventilator circuit. ${ }^{24}$ The aim of this study was to compare these two different breath sampling techniques on a circuit optimised for breath VOC collection, utilising a test-lung device as a model for patient settings in the ICU. We hypothesized that by sampling at a position further upstream (nearer to the patient) within the ventilator circuit, larger abundances of VOCs would be detectable as they are measured closer to their source of origin. In order to evaluate the results from the test circuit, detection limits are compared to VOC levels obtained from patients enrolled in the National Institute for Health Research (NIHR) BRAVo (BReath Analysis in Intensive Care: Proof of Concept for Non-Invasive Diagnosis of Ventilator Associated Pneumonia) project.

\section{Methods}

\section{Study outline}

The research plan comprised: (1) the construction of a ventilator circuit using a "dummy" lung that integrated equipment for both sampling methods; (2) introduction of a mix of VOCs (representative of human breath) into the circuit for sorbent tube sampling and analysis; and (3) comparison of the analytical limits of the system for both methods to breath data sampled from 40 patients recruited at two centres participating in the BRAVo study.

\section{The ventilator test circuit}

The ventilator test circuit consisted of a mechanical ventilator (840 Puritan Bennett, Carlsbad, CA, USA), a Heat and Moisture Exchanger (HME; Intersurgical, Wokingham, UK), a closed suction catheter (three brands were tested, from: Westbourne Medical Ltd, Cheadle, UK (from now on referred to as 'catheter 1'); GB UK Healthcare, Selby, UK (catheter 2); and KimberlyClark, West Malling, UK (catheter 3)) and an endotracheal tube size 8 (Smiths-Medical, Ashford, UK) in line with a test lung device (MAQUET, Solna, Sweden), connected with polyfluoroacetylene (PFA) tubing (type PFA-T2-030-100:1/8" OD and
PFA-T4-062-100:1/4" OD, Swagelok, Warrington, UK). A small piece of corrugated tubing - delivered in the same package as catheter 3 - was inserted between the endotracheal tube and test lung device to mimic anatomical dead space. The ventilator circuit was connected to cylinders of $\mathrm{O}_{2}$ and medical air (BOC Ltd, Middlesbrough, UK). The mechanical ventilator was set at a pressure-controlled mode with positive end-expiratory pressure (PEEP) $6.0 \mathrm{~cm} \mathrm{H}_{2} \mathrm{O}$, peak inspiratory pressure $23 \mathrm{~cm}$ $\mathrm{H}_{2} \mathrm{O}$, tidal volume $400 \mathrm{~mL}$, frequency 12 breaths per min, inspiratory-to-expiratory time ratio $1: 2,100 \% \mathrm{O}_{2}$.

A schematic representing the ventilator circuit is displayed in Fig. 1. Two breath sampling methods were investigated: (A) a non-invasive technique collecting air from the external ventilator connection circuit based on ref. 20 and (B) a semi-invasive technique using a suction catheter inserted via the endotracheal tube based on ref. 11. Using a precision air-sampling pump (Escort ELF pump, Supelco, Dorset, UK), air samples of $1.2 \mathrm{~L}$ were collected at a flow of $0.5 \mathrm{~L} \mathrm{~min}^{-1}$ using $100 \% \mathrm{O}_{2}$ in order to mimic ICU setting. Air was drawn through stainless steel tubes ( 0.25 inch outer diameter, 3.5 inch length) packed with $200 \mathrm{mg} \pm 1.7 \%$ of TenaxGR adsorbent (35/60, Markes International, Llantrisant, UK). TenaxGR was chosen for its hydrophobic properties.

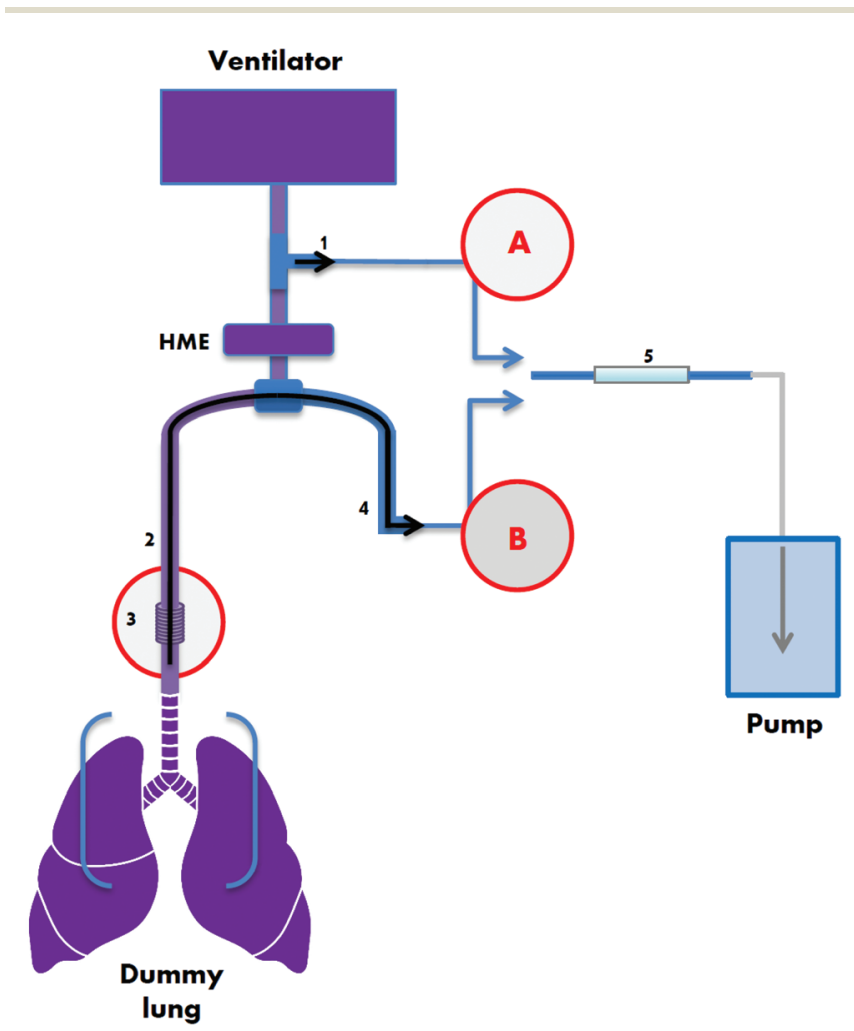

Fig. 1 Schematic overview of the ventilator circuit. The non-invasive technique (A) collects air diverted through the side limb of the circuit. The semi-invasive method (B) samples air from the endotracheal tubing via a suction catheter; the position of the tip of the suction catheter is indicated by the end of the solid black line below component number 3 . 1: T-piece connector; 2: endotracheal tube; 3 : dead space; 4: suction catheter; 5: steel sorbent tube; A: non Invasive sampling site; B: semiinvasive sampling technique. 
For the semi-invasive sampling method B (Fig. 1, red circled B) "inspiratory" airflow followed the route (in consecutive order): air $/ \mathrm{O}_{2}$ cylinder - air $/ \mathrm{O}_{2}$ mechanical ventilator hoses (3 $\mathrm{M}$ air hose and $3 \mathrm{M} \mathrm{O}_{2}$ hose; MEC Medical Ltd, Hitchin, UK) - mechanical ventilator - corrugated tubing (Intersurgical) - T-piece connector (GE Healthcare Finland, Helsinki, Finland) - HME - closed suction catheter - endotracheal tube - small piece of corrugated tubing - test lung device. During the simulation of expiration and subsequent air sampling, the route was as follows: test lung device - small piece of corrugated tubing - endotracheal tube closed suction catheter - PFA tubing (approximately $50 \mathrm{~cm}$ PFA-T2-030-100:1/8" OD, both ends connected to approximately $8 \mathrm{~cm}$ of PFA-T4-062-100:1/4" OD; Swagelok, Warrington, UK) steel adsorbent tube. The inspiratory airflow route for the noninvasive method (Fig. 1, red circled A) was: air $/ \mathrm{O}_{2}$ cylinder - air $/ \mathrm{O}_{2}$ mechanical ventilator hoses - mechanical ventilator - corrugated tubing (Intersurgical) - T-piece connector (GE Healthcare Finland) - HME - endotracheal tube - small piece of corrugated tubing - test lung device. The expiratory route was: test lung device - small piece of corrugated tubing - endotracheal tube HME - T-piece connector - PTFE tubing - steel adsorbent tube. Before attaching the steel adsorbent tubes and collecting air samples the apparatus was purged for $1 \mathrm{~min}$ at $0.5 \mathrm{~L} \mathrm{~min} \mathrm{~m}^{-1}$. Experiments were performed at Salford Royal Hospital NHS Foundation Trust, UK.

In order to investigate the extent to which different materials give rise to analytical contamination, three brands of closed suction catheter were tested within the circuit as above. Filtered room air was purged through each system and col- lected onto sorbent tubes. Two of these catheters (catheter 2 and 3) were used to acquire breath from ICU patients at the two Manchester sites; these measurements therefore provided the background signal from which detection limits were ascertained.

\section{VOC test mix}

A VOC mix (Table 1) was designed to test the dummy lung system against a wide range of compounds relevant to breath. The 24 component mix, an extended panel based on the standard described by Basanta et al., ${ }^{25}$ comprised compounds of various chemical classes to examine how analytical performance and sampling efficiency changes with properties such as polarity and solubility. For example, the heterocyclic compound 1,4-dioxane was included as it was previously reported as an endogenous component in mechanically ventilated patients' breath ${ }^{20}$ whilst the bicyclic monoterpene 3-carene was included as it has been identified as elevated in the breath of infected mechanically ventilated patients. ${ }^{11}$ VOCs were dissolved in high purity methanol (HPLC grade) and stock concentrations were determined from calibration curves selecting the concentration above the limit of quantification. Following serial dilution, different concentrations were injected into the dummy lung system $(20 \mu \mathrm{L})$ inside extendable tubing that connected the endotracheal tube to the dummy lung (position element 3 on Fig. 1). Following injection of the VOC mix into the dummy lung system, samples were collected on adsorbent tubes and analysed by TD-GC-MS. A calibration standard loading rig (CSLR, Markes) was used to load the same concen-

Table 1 Physical and chemical properties of the VOC test mix

\begin{tabular}{|c|c|c|c|c|c|c|c|}
\hline Compound & Conc. in $1^{\circ}$ stock/(mmol) & $\mathrm{RMM} /\left(\mathrm{g} \mathrm{mol}^{-1}\right)$ & Quant ion & $\mathrm{RT}(\mathrm{min})$ & $\log \left(K_{\mathrm{OW}}\right)$ & 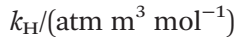 & $\mathrm{VP} /(\mathrm{mmHg})$ \\
\hline Acetone & 100 & 58 & 58 & 1.72 & -0.24 & $3.50 \times 10^{-5}$ & $2.32 \times 10^{2}$ \\
\hline Isoprene & 100 & 68 & 67 & 1.73 & 2.42 & $7.67 \times 10^{-2}$ & $5.50 \times 10^{2}$ \\
\hline Benzene & 25 & 78 & 78 & 2.4 & 2.13 & $5.55 \times 10^{-3}$ & $9.48 \times 10^{1}$ \\
\hline 3-Pentanone & 25 & 86 & 57 & 2.66 & 0.91 & $8.36 \times 10^{-5}$ & $3.77 \times 10^{1}$ \\
\hline 1,4-Dioxane & 55 & 88 & 88 & 2.77 & -0.27 & $4.80 \times 10^{-6}$ & $3.81 \times 10^{1}$ \\
\hline Pyridine & 25 & 79 & 79 & 3.18 & 0.65 & $1.10 \times 10^{-5}$ & $2.08 \times 10^{1}$ \\
\hline Toluene & 10 & 92 & 91 & 3.49 & 2.73 & $6.64 \times 10^{-3}$ & $2.84 \times 10^{1}$ \\
\hline Octane & 25 & 114 & 85 & 3.94 & 5.18 & $3.21 \times 10^{0}$ & $1.41 \times 10^{1}$ \\
\hline Butyl acetate & 25 & 116 & 56 & 4.2 & 1.78 & $2.81 \times 10^{-4}$ & $1.15 \times 10^{1}$ \\
\hline$p$-Xylene & 25 & 106 & 91 & 5.27 & 3.15 & $6.90 \times 10^{-3}$ & $8.84 \times 10^{0}$ \\
\hline Nonane & 25 & 128 & 57 & 5.87 & 5.65 & $3.40 \times 10^{0}$ & $4.45 \times 10^{0}$ \\
\hline Benzaldehyde & 25 & 106 & 77 & 7.31 & 1.48 & $2.67 \times 10^{-5}$ & $1.27 \times 10^{0}$ \\
\hline 1-Heptanol & 25 & 116 & 70 & 7.51 & 2.62 & $1.88 \times 10^{-5}$ & $2.34 \times 10^{-1}$ \\
\hline Decane & 25 & 142 & 57 & 8.27 & 5.01 & $5.15 \times 10^{0}$ & $1.43 \times 10^{0}$ \\
\hline 3-Carene & 10 & 136 & 93 & 8.56 & 4.38 & $1.07 \times 10^{-1 b}$ & $2.09 \times 10^{0 c}$ \\
\hline Limonene & 25 & 136 & 68 & 9.03 & 4.38 & $3.19 \times 10^{-2}$ & $1.44 \times 10^{0}$ \\
\hline Undecane & 10 & 156 & 57 & 10.83 & $5.74^{a}$ & $1.93 \times 10^{0}$ & $4.12 \times 10^{-1}$ \\
\hline Nonanal & 50 & 142 & 57 & 10.94 & $3.27^{b}$ & $7.37 \times 10^{-4}$ & $3.70 \times 10^{-1}$ \\
\hline Tetralin & 10 & 132 & 104 & 12.46 & 3.49 & $1.36 \times 10^{-3}$ & $3.68 \times 10^{-1}$ \\
\hline Dodecane & 10 & 170 & 57 & 13.37 & 6.10 & $8.18 \times 10^{0}$ & $1.35 \times 10^{-1}$ \\
\hline 1-Methylindole & 10 & 131 & 130 & 15.17 & 2.72 & $1.89 \times 10^{5 b}$ & $4.71 \times 10^{-2 d}$ \\
\hline Tridecane & 10 & 184 & 57 & 15.81 & 6.73 & $2.88 \times 10^{0}$ & $5.58 \times 10^{-2}$ \\
\hline Tetradecane & 10 & 198 & 57 & 18.13 & 7.20 & $9.20 \times 10^{0}$ & $1.16 \times 10^{-2}$ \\
\hline Pentadecane & 10 & 212 & 57 & 20.33 & $7.71^{a}$ & $1.26 \times 10^{1}$ & $3.43 \times 10^{-3}$ \\
\hline
\end{tabular}

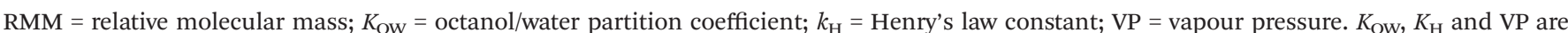

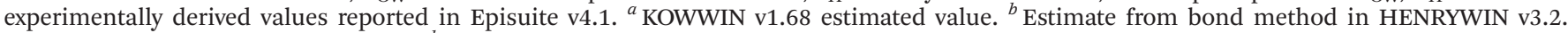
${ }^{c}$ Mean of Antoine and Grain methods. ${ }^{d}$ Modified Grain method. 
tration range of the test mix directly onto sorbent tubes, to allow comparison of peak intensities of target VOCs to results from the test circuit, and thus determine the mass of VOCs recovered at each sampling point.

\section{Breath sampling}

In order to evaluate results from the dummy lung experiments against realistic, meaningful data, a subset of samples collected as part of the BRAVo project were examined. During BRAVo, mechanically ventilated patients provided breath samples within 24 hours of clinical suspicion of ventilatorassociated pneumonia (VAP). The first 20 patients recruited at two centres participating in the study (Manchester University NHS Foundation Trust - Manchester Royal Infirmary, and Salford Royal NHS Foundation Trust in Manchester, UK) were included in this analysis. These results have been used only to provide a representative dataset of exhaled VOC concentration samples distributions in mechanically ventilated patients (irrespective of clinical status) and an in-depth analysis of the VOC results is beyond the scope of the present study. Patient information letters, informed consent forms and the study protocol were approved by the National Health Service Research Ethics Committee (reference 15/NW/0393). Formal assent was sought with a designated consultee at time of inclusion and deferred consent was obtained for patients who regained capacity.

Both methods were used to sample breath at the two sampling sites: $1.2 \mathrm{~L}$ of breath was collected at a flow of $0.5 \mathrm{~L}$ $\min ^{-1}$ onto TenaxGR adsorbent tubes (Markes International, Llantrisant, UK). Samples were collected in duplicate (i.e., 40 samples were submitted from each centre for each sampling method). After sampling, the tubes were returned to the Manchester Institute of Biotechnology, University of Manchester, UK, for analysis by TD-GC-MS.

\section{Thermal desorption gas chromatography-mass spectrometry}

TenaxGR adsorbent tubes were analysed by thermal desorptiongas chromatography-mass spectrometry (TD-GC-MS). A two stage desorption process was performed based on the parameters outlined in Table 2. Prior to analysis all tubes were loaded with an internal standard $(100 \mu \mathrm{L}$ of $1 \mathrm{ppmV} p$-bromofluorobenzene in $\mathrm{N}_{2}$ ) and all tubes were desorbed twice to determine carryover and for assurance that efficient desorption had taken place.

A targeted deconvolution was performed on 0.1 min time windows surrounding the retention times presented in Table 1 and target quantifier ions were integrated using MassHunter's Agile2 integrator (Agilent Technologies, Stockport, UK).

\section{Results}

Realistic steady state mechanical ventilation rates and breath pressure-volume loops were established in the ventilator circuit. By comparing peak intensities of target VOCs to results from direct injections of the test mix onto sorbent tubes, the mass of VOCs recovered at both sampling points could be ascertained (Fig. 2). All calibration curves were linear over several orders of magnitude. Also apparent in Fig. 2 is the clear difference in recovery between sampling methods: the semi-invasive method (method B) is associated with more VOC recovery onto the sorbent tubes.

\section{Comparing abundances of target VOCs between both sampling methods}

By plotting masses recovered using method B versus method A, a clear relationship was observed whereby only $60 \%$ of the VOC mass collected using method B (the semi-invasive method) was recovered for method A (the non-invasive method) (Fig. 3). This relationship held for most VOCs, regardless of compound class. This is consistent with the sampling position for method B: as it is located further upstream within the ventilator circuit, analytes are subjected to less turbulent mixing with deadspace air as they are collected closer to their source. The compounds that deviated from this were 1-methylindole, 1-heptanol, and benzaldehyde, where much lower pro-

Table 2 Details of the TD GC-MS method

\begin{tabular}{|c|c|c|}
\hline Thermal desorption unit & $\begin{array}{l}\text { Model } \\
\text { Cold trap model } \\
\text { Cold trap temp } \\
\text { Primary desorb } \\
\text { Secondary desorb }\end{array}$ & $\begin{array}{l}\text { Markes International TD100 } \\
\text { U-T11GPC-2S general purpose carbon (Markes International) } \\
0^{\circ} \mathrm{C} \\
280^{\circ} \mathrm{C} \text { for } 5 \text { min (splitless) } \\
280^{\circ} \mathrm{C} \text { for } 3 \mathrm{~min} \text { (splitless) }\end{array}$ \\
\hline Chromatography instrument & $\begin{array}{l}\text { Model } \\
\text { Column model } \\
\text { Carrier gas } \\
\text { Oven program } \\
\text { Postrun }\end{array}$ & $\begin{array}{l}\text { Agilent 7890B GC } \\
\text { DB-5 ms GC }(0.25 \mu \mathrm{m}, 0.25 \mathrm{~mm} \times 30 \mathrm{~m} \text {; Agilent Technologies }) \\
\text { Constant pressure }(10 \mathrm{kPa}) \mathrm{He} \\
\text { Initial temperature of } 40^{\circ} \mathrm{C} ; 170^{\circ} \mathrm{C} \text { at } 6^{\circ} \mathrm{C} \mathrm{min}{ }^{-1} ; 190{ }^{\circ} \mathrm{C} \text { at } 15^{\circ} \mathrm{C} \mathrm{min}{ }^{-1} \\
250^{\circ} \mathrm{C}(2 \mathrm{~min})\end{array}$ \\
\hline Mass spectrometer & $\begin{array}{l}\text { Model } \\
\text { Source } \\
\text { Scan } m / z \text { range }\end{array}$ & $\begin{array}{l}\text { Agilent } 7010 \text { series triple quadrupole mass spectrometer } \\
\mathrm{EI}+\text { at } 70 \mathrm{eV}\left(200^{\circ} \mathrm{C}\right) \\
40-500(5 \mathrm{~Hz})\end{array}$ \\
\hline Reconditioner & $\begin{array}{l}\text { Model } \\
\text { Carrier gas } \\
\text { Oven program } \\
\text { Dry purge (when required) }\end{array}$ & $\begin{array}{l}\text { Markes TC20 } \\
50 \mathrm{~mL} \min ^{-1} \mathrm{~N}_{2} \\
3300^{\circ} \mathrm{C} \text { for } 1 \mathrm{~h} \\
50 \mathrm{~mL} \min ^{-1} \mathrm{~N}_{2} \text { for } 4 \mathrm{~min}\end{array}$ \\
\hline
\end{tabular}



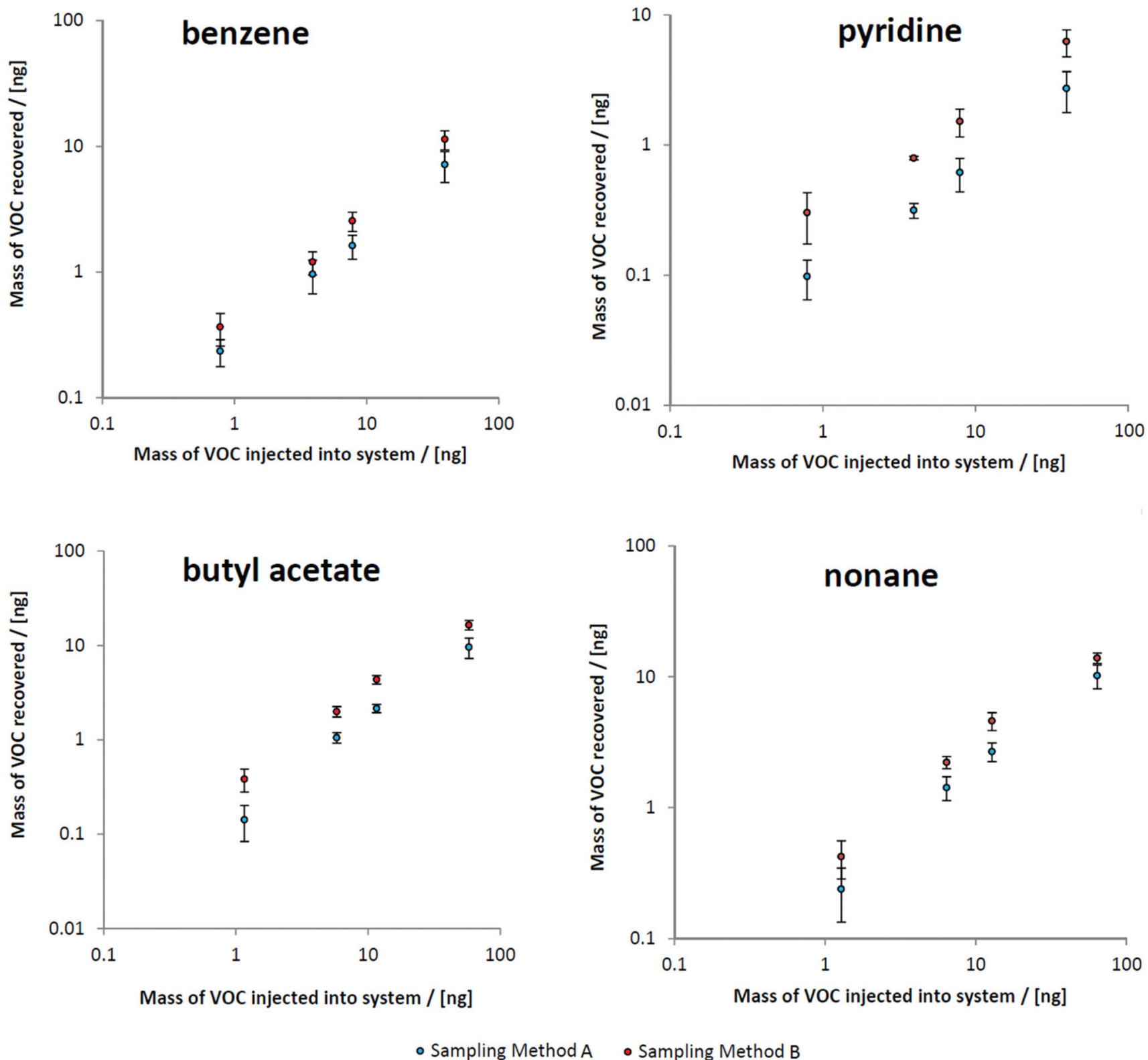

Fig. 2 The amount of VOCs collected onto sorbent tubes versus the amount of VOCs injected into the dummy lung system, for both sampling methods. Sampling method $A=$ non-invasive; sampling method $B=$ closed suction catheter semi-invasive method. Points are the mean of 3 measurements and error bars show standard deviations.

portions of VOCs were sampled using method A compared to method $\mathrm{B}$ (at $2 \%, 15 \%$, and $24 \%$ respectively). These compounds all exhibit a combination of $k_{\mathrm{H}}$ below $1 \times 10^{-4} \mathrm{~atm} \mathrm{~m}^{3} \mathrm{~mol}^{-1}$ and low vapour pressure (approximately $1 \mathrm{mmHg}$ or less) and thus likely reflect interaction between breath VOCs and the materials and surfaces within the ventilator circuit, thus exaggerating the loss of recovery with further distance from source.

\section{Comparing contaminating signals associated with the use of} different closed suction catheters

When different closed suction catheters were integrated into the dummy lung circuit, very different background signals were observed. Catheters must be flexible for use and are therefore constructed from elastomers and silicon based plastics, which are often associated with the emission of solvents and volatile species. Table 3 shows the VOCs that gave rise to the largest signals for each brand of catheter. All compounds were identified based on their match hit with the NIST 14 library (>800 reverse match) and are therefore considered MSI level 2. ${ }^{26}$ Observed $n$-alkane retention indices compare well with literature values (comparable to the tolerance observed for the MSI level 1 compounds reported in Table 4). Several compounds are common to all three catheters, however the pattern of their emission differs markedly. For example, cyclo- 


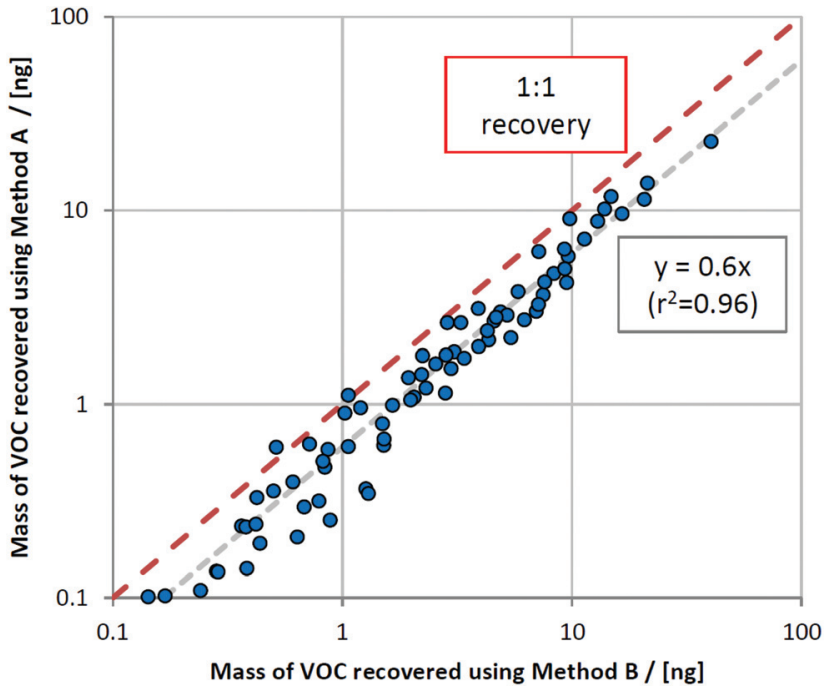

Fig. 3 Mass of VOCs recovered using the non-invasive method (method A) versus the semi-invasive method (method B), for all VOCs in the mix except for 1-methylindole, 1-heptanol, and benzaldehyde. Grey dashed line $=$ line of best fit; red dashed line $=$ unity gradient $(y=x)$. hexanone, 2-ethyl-1-hexanol and cyclic siloxanes all make up for a significant proportion of the total ion count (TIC). Whilst these, alongside compounds such as 1,2-dichloroethane, are widely considered to be exogenous species, other compounds such as 2-butanone and monoterpenes may potentially be important breath markers.

\section{Comparing analytical limits between sampling methods}

Table 4 shows the method detection limits (MDLs) calculated for each sampling method $(3 \sigma)$ and for the two sites where patients were recruited. The results from the dummy lung work were generalized to apply to both sites for method A. For method B, two sets of MDLs were obtained one for each centre, representing the different brands of closed suction catheter used in their equipment. A wide range of MDLs are presented in Table 4 reflecting not only the direct interference from gases such as 3-carene that are emitted by the suction catheter, but also indirect interference from co-eluting compounds. This is apparent on examination of the retention indices presented in Table 4, calculated from breath samples

Table 3 The top 10 most abundant species analysed in background air using sampling method B with three different catheters

\begin{tabular}{|c|c|c|c|c|c|}
\hline & VOCs associated with catheter 1 (\% TIC) & $\mathrm{RT} /(\min )$ & $\mathrm{RI}_{\mathrm{obs}}$ & $\mathrm{RI}_{\text {Lit }}$ & $\Delta_{\mathrm{RT}} /(\mathrm{s})$ \\
\hline 1 & Cyclohexanone (10\%) & 5.8 & 895 & 891 (ref. 27) & 4 \\
\hline 2 & 2-Ethyl-1-hexanol (7\%) & 9.0 & 1029 & 1035 (ref. 28) & 9 \\
\hline 3 & 1,3-Di-tert-butylbenzene ( $5 \%)$ & 14.8 & 1258 & 1249 (ref. 29) & 13 \\
\hline 4 & Dodecamethylcyclopentasiloxane (4\%) & 16.5 & 1329 & 1341 (ref. 30) & 17 \\
\hline 5 & 3 -Carene $(3 \%)$ & 8.6 & 1011 & 1010 (ref. 31) & 2 \\
\hline 6 & Decamethylcyclopentasiloxane (3\%) & 12.2 & 1156 & 1165 (ref. 30) & 13 \\
\hline 7 & $p$-Xylene $(3 \%)$ & 5.3 & 868 & 865 (ref. 31) & 3 \\
\hline 8 & $\alpha$-Pinene $(3 \%)$ & 6.7 & 934 & 939 (ref. 32) & 8 \\
\hline 9 & 1,2-Dichloroethane (3\%) & 2.3 & 648 & 649 (ref. 33) & 0 \\
\hline \multirow[t]{2}{*}{10} & 3,7-Dimethylnonane $(2 \%)$ & 9.2 & 1035 & 1036 (ref. 34) & 2 \\
\hline & VOCs associated with catheter 2 (\% TIC) & $\mathrm{RT} /(\min )$ & $\mathrm{RI}_{\mathrm{obs}}$ & $\mathrm{RI}_{\text {Lit }}$ & $\Delta_{\mathrm{RT}} /(\mathrm{s})$ \\
\hline 1 & Cyclohexanone (21\%) & 5.8 & 894 & 891 (ref. 27) & 3 \\
\hline 2 & Decamethylcyclopentasiloxane (9\%) & 12.3 & 1158 & 1165 (ref. 30) & 11 \\
\hline 3 & Dodecamethylcyclopentasiloxane (6\%) & 16.5 & 1328 & 1341 (ref. 30) & 17 \\
\hline 4 & 2-Ethyl-1-hexanol (6\%) & 9.0 & 1030 & 1035 (ref. 28) & 8 \\
\hline 5 & Tetradecamethylcycloheptasiloxane (5\%) & 20.3 & 1500 & 1516 (ref. 30) & 21 \\
\hline 6 & $\alpha$-Pinene $(4 \%)$ & 6.7 & 934 & 939 (ref. 32) & 7 \\
\hline 7 & $\beta$-Pinene $(4 \%)$ & 7.7 & 978 & 980 (ref. 35) & 3 \\
\hline 8 & Ethyl acetate (3\%) & 2.1 & 614 & 612 (ref. 31) & 1 \\
\hline 9 & Isophorone $(2 \%)$ & 11.4 & 1122 & 1124 (ref. 28) & 2 \\
\hline \multirow[t]{2}{*}{10} & p-Xylene $(2 \%)$ & 5.3 & 868 & 865 (ref. 31) & 4 \\
\hline & VOCs associated with catheter 3 (\% TIC) & $\mathrm{RT} /(\min )$ & $\mathrm{RI}_{\mathrm{obs}}$ & $\mathrm{RI}_{\text {Lit }}$ & $\Delta_{\mathrm{RT}} /(\mathrm{s})$ \\
\hline 1 & Dodecamethylcyclopentasiloxane (11\%) & 16.5 & 1328 & 1341 (ref. 30) & 17 \\
\hline 2 & Decamethylcyclopentasiloxane (11\%) & 12.3 & 1158 & 1165 (ref. 30) & 11 \\
\hline 3 & Tetradecamethylcycloheptasiloxane (10\%) & 20.3 & 1500 & 1516 (ref. 30) & 21 \\
\hline 4 & 2-Ethyl-1-hexanol (5\%) & 9.0 & 1029 & 1035 (ref. 28) & 9 \\
\hline 5 & 2,5-Dimethylhexane-2,5-dihydroperoxide (5\%) & 17.3 & 1365 & $1367^{a}$ & 3 \\
\hline 6 & Cyclohexanone (5\%) & 5.8 & 894 & 891 (ref. 27) & 6 \\
\hline 7 & 2-Butanone (3\%) & 2.0 & 601 & 602 (ref. 32) & 0 \\
\hline 8 & $p$-Xylene $(3 \%)$ & 5.3 & 868 & 865 (ref. 32) & 3 \\
\hline 9 & Acetone $(3 \%)$ & 1.7 & 500 & 500 (ref. 32) & 0 \\
\hline 10 & Dodecane (3\%) & 13.4 & 1200 & 1200 & 1 \\
\hline
\end{tabular}

The VOCs printed in italics are shared between the three suction catheters. ${ }^{a}$ Estimated $n$ alkane retention index reported in NIST v14. RI ${ }_{\text {obs }}$ is the retention index calculated from observed retention times; $\mathrm{RI}_{\mathrm{lit}}$ is the retention index reported in literature; $\Delta_{\mathrm{RT}}$ is the difference between the observed retention time and the retention time calculated from $\mathrm{RI}_{\text {lit }}$. 
Table 4 Retention indices and method detection limits for VOCs sampled in the ICU

\begin{tabular}{|c|c|c|c|c|c|c|c|c|}
\hline \multirow[b]{2}{*}{ Compound } & \multirow[b]{2}{*}{$\mathrm{RI}_{\mathrm{Obs}}$} & \multirow[b]{2}{*}{$\mathrm{RI}_{\text {Lit }}$} & \multirow[b]{2}{*}{$\Delta_{\mathrm{RT}} /(\mathrm{s})$} & \multirow{2}{*}{$\begin{array}{l}S_{\mathrm{RI}} \\
\text { Method B }\end{array}$} & \multirow{2}{*}{$\begin{array}{l}S_{\mathrm{RI}} \\
\text { Method A }\end{array}$} & \multicolumn{3}{|c|}{ Method detection limit/ppbV } \\
\hline & & & & & & Method B (site 1) & Method B (site 2) & Method A (both sites) \\
\hline Acetone & 504 & 500 (ref. 31) & 1 & 8 & 6 & 6.28 & 5.60 & 1.25 \\
\hline Isoprene & 515 & 520 (ref. 36) & 1 & 9 & 7 & 0.10 & 0.22 & 0.21 \\
\hline Benzene & 660 & 657 (ref. 31) & 1 & 2 & 2 & 0.09 & 0.25 & 0.13 \\
\hline 3-Pentanone & 700 & 689 (ref. 31) & 4 & 7 & 7 & 2.13 & 1.11 & 1.39 \\
\hline 1,4-Dioxane & 707 & 705 (ref. 37) & 2 & 1 & 1 & 0.02 & 0.13 & 0.12 \\
\hline Pyridine & 740 & 736 (ref. 31) & 3 & 3 & 3 & 0.12 & 0.14 & 0.06 \\
\hline Toluene & 764 & 760 (ref. 31) & 3 & 0 & 1 & 0.17 & 0.19 & 0.14 \\
\hline Octane & 800 & 800 & & & & 0.14 & 0.10 & 0.12 \\
\hline Butyl acetate & 813 & 811 (ref. 32) & 2 & 6 & 1 & 0.03 & 0.05 & 0.06 \\
\hline$p$-Xylene & 868 & 865 (ref. 31) & 3 & 29 & 0 & 2.80 & 4.20 & 0.48 \\
\hline Nonane & 900 & 900 & & & & 0.09 & 0.03 & 0.13 \\
\hline Benzaldehyde & 961 & 960 (ref. 32) & 2 & 8 & 1 & 1.00 & 0.39 & 1.33 \\
\hline 1-Heptanol & 969 & 969 (ref. 31) & 1 & 6 & 1 & 0.56 & 0.21 & 0.55 \\
\hline Decane & 1000 & 1000 & & & & 0.35 & 2.36 & 0.32 \\
\hline 3-Carene & 1011 & 1010 (ref. 31) & 1 & 1 & 1 & 3.46 & 1.29 & 0.13 \\
\hline Limonene & 1030 & 1031 (ref. 38) & 2 & 1 & 0 & 0.77 & 1.18 & 0.45 \\
\hline Undecane & 1100 & 1100 & & & & 0.83 & 0.15 & 0.28 \\
\hline Nonanal & 1105 & 1105 (ref. 38) & 1 & 1 & 0 & 2.67 & 0.60 & 1.96 \\
\hline Tetralin & 1165 & 1163 (ref. 27) & 3 & 1 & 1 & 0.10 & 0.06 & 0.02 \\
\hline Dodecane & 1200 & 1200 & & & & 0.11 & 0.80 & 0.30 \\
\hline 1-Methyl indole & 1276 & 1273 (ref. 27) & 4 & 5 & 5 & 0.02 & 0.01 & 0.01 \\
\hline Tridecane & 1300 & 1300 & & & & 0.11 & 0.03 & 0.49 \\
\hline Tetradecane & 1400 & 1400 & & & & 0.08 & 0.13 & 0.32 \\
\hline Pentadecane & 1500 & 1500 & & & & 0.01 & 0.01 & 0.09 \\
\hline
\end{tabular}

$\mathrm{RI}_{\mathrm{obs}}=$ retention indices calculated from breath samples; $\mathrm{RI}_{\mathrm{lit}}=$ literature retention index; $\Delta_{\mathrm{RT}}$ is the difference between the observed retention time and the retention time calculated from $\mathrm{RI}_{\mathrm{lit}} ; S_{\mathrm{RI}}$ is the standard deviation in retention indices.

collected from mechanically ventilated patients. For both methods, early-eluting compounds are associated with a wider spread of RI values. These compounds elute in a busy part of the chromatogram during trap injection. However, midway through the chromatograms the spread in RI values becomes much wider for method B (particularly for the compound $p$-xylene, also listed in Table 3).

\section{Comparing analytical limits to breath data}

To evaluate the MDLs listed in Table 4, data obtained following the analysis of breath from 40 mechanically ventilated patients were investigated to determine the proportion of results above the MDLs for both sampling methods (Fig. 4). Whilst based on Fig. 2 the selected compounds all displayed a greater degree of VOC recovery for method B, the findings represented in Fig. 4 exemplify the complexity of the system under study. Benzene, for example, has a higher proportion of results above the MDL for method $\mathrm{B}$ at site 1 . Conversely, at site 2, a higher proportion of results are above the MDL for method A. Benzene, a known trap artefact, is likely to be affected by the presence of the closely eluting compound, 1,2dichloroethane. Pyridine provides another example where background contamination likely affects the MDL and at both sites method A appears to be more successful in detecting the compound. Butyl acetate is associated with the opposite effect; in this case the larger recovery of exhaled VOCs obtained by method B leads to better MDLs and higher proportions of the compound are detected. Similarly the same effect is observed for nonane, albeit with a smaller proportion of the dataset measured at levels above the MDL.

Fig. 5 displays the proportion of the breath dataset above the MDL for all 24 compounds under study. At site 1, using method B to sample breath resulted in a significant increase in the number of compounds measured at detectable levels. Method A and method B are better suited to sampling different compounds however at site 2, the proportion of the data set above the MDL is approximately even. In this regard, the two sampling techniques complemented one another. A full evaluation of the suitability of these sampling methods towards sampling breath in mechanically ventilated patients may only be possible when target compounds have been identified and biomarkers indicative of infection are known.

\section{Discussion}

A ventilator circuit was constructed that enabled thorough ex vivo testing of two methods for capturing breath in mechanically ventilated patients. A clear difference in VOC recovery was seen between both sampling methods: method B (the semi-invasive method) was associated with larger abundances of VOCs sampled onto the sorbent tubes, compared to the non-invasive method.

The dynamic range of the system appeared to cover several orders of magnitude, appropriate for the wide concentration distributions frequently observed in breath research. The observed larger absolute sensitivities for method B (the semi- 

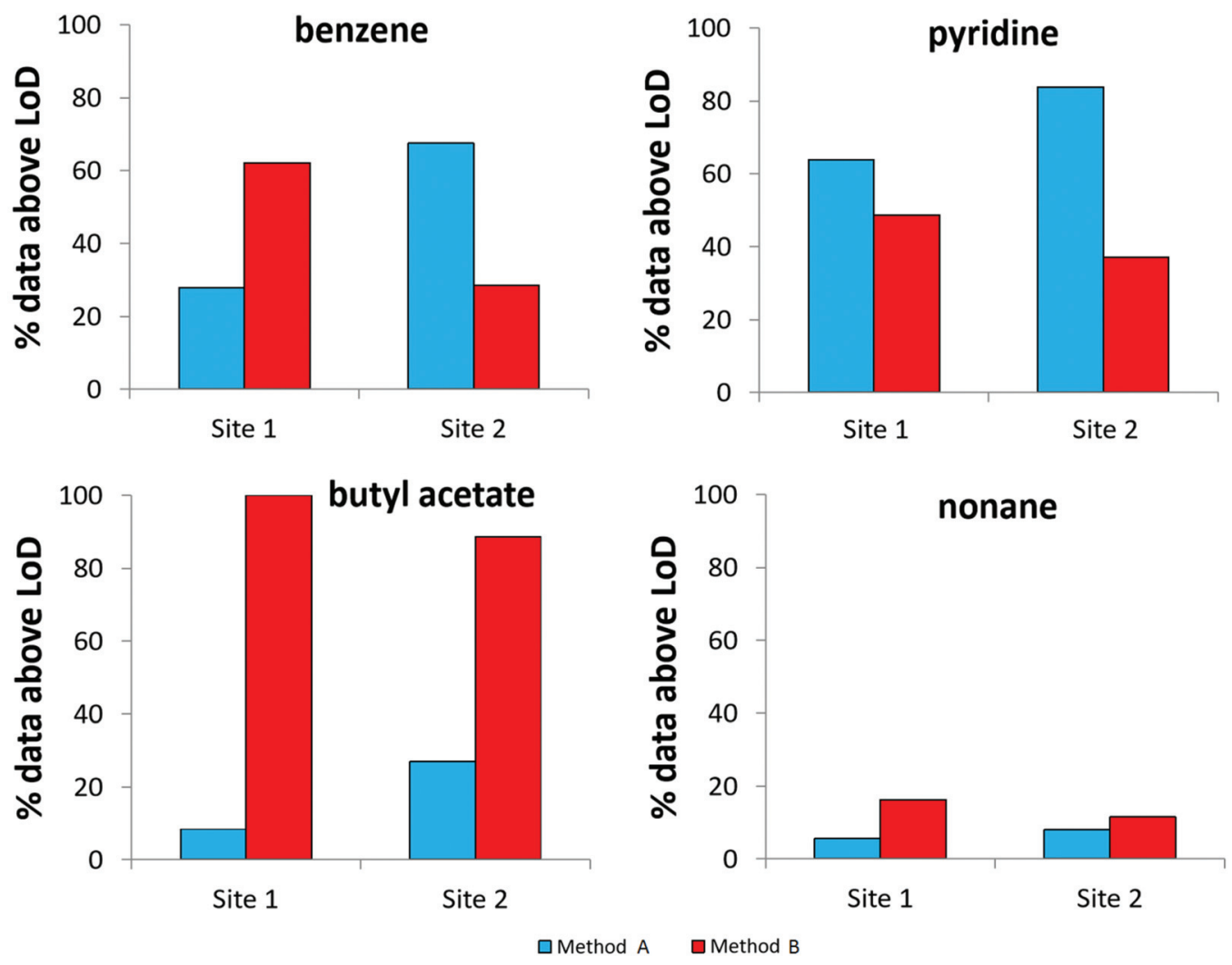

Fig. 4 The proportion of results above the MDL for both sampling methods used to obtain breath samples from two ICUs ( $N=40,2$ replicates at each site).

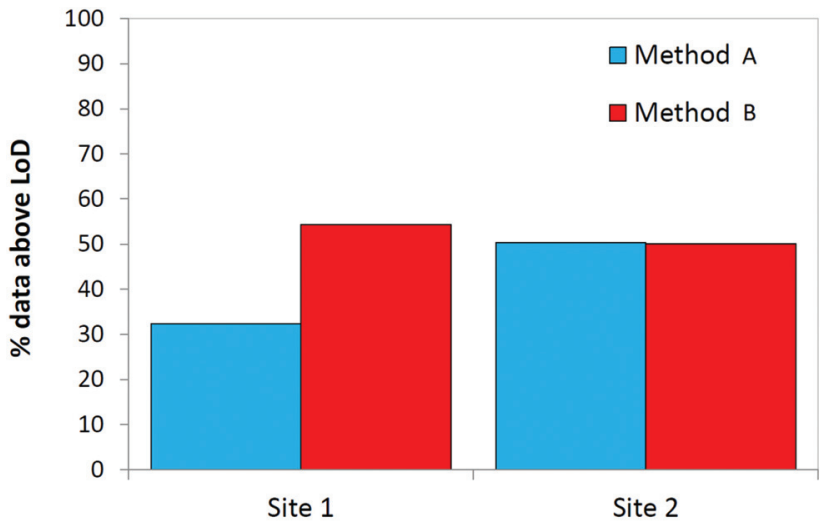

Fig. 5 The proportion of results above the MDL for both sampling methods used to obtain breath samples from two ICUs based on all 24 compounds under study ( $N=40,2$ replicates at each site).

invasive sampling method) are likely explained by the proximity to the sampling position closer to the source of origin of the VOCs. Also the position of the HME filter (between the source of VOCs and the sampling tube) may contribute to a lower absolute sensitivity for method A. Several less volatile, more polar species were recovered in significantly lower proportions using the non-invasive method compared to the semi-invasive method, likely reflecting interaction between breath VOCs and surfaces downstream of the ventilator circuit. However, this enhancement in recovery for method B did not necessarily translate to better MDLs, largely due to interference from contaminants within the sample matrix.

The two ICUs use different closed suction catheters (employed in method B), giving rise to varying levels of analytical contamination. These contaminants affected MDLs, either directly as exogenous sources of VAP-relevant species, or indirectly by affecting the chromatography of target compounds. Exploratory experiments whereby suction catheters were purged for over an hour showed a reduction in contamination (data not shown), however a significant proportion still remained. The catheters used in mechanically ventilated patients must be flexible in order to follow the anatomical routes of the upper respiratory system, and clinical ICU practice is restricted to CE marked equipment. Therefore, replacing the catheters with bespoke tubing made from lower emitting but more rigid materials (e.g., PTFE) is not an option. One of the most abundant VOCs emitted in catheter headspace was cyclohexanone, an organic solvent involved in the production process of certain medical devices containing polyvinyl chloride (e.g. endotracheal tubes, intravenous fluid bags, extracorporeal circulation tubing), ${ }^{39}$ and has been specifically related to patients receiving mechanical ventilation. ${ }^{40}$ Other high con- 
centration species included several methylcyclosiloxanes, likely emanating from silicon elastomers built in to the catheters. Whilst compounds such as 2-ethyl-1-hexanol and isophorone may be considered exogenous species (the former is used to produce plasticizers whilst the latter is a polymer precursor), the extent to which they are produced in the body is unknown. To our knowledge, only one other study has described validation experiments in which air was sampled from a ventilator circuit in a laboratory. ${ }^{24}$ Low concentrations of 15 VOCs were found in medical air including cyclohexanone. The researchers did not consider this contamination to have substantially influenced the results of their clinical study investigating breath sampling in mechanically ventilated patients.

In many cases the LoDs in Table 4 were larger for method B than those associated with method A. This is due to the amount of contaminating signal on the chromatograms associated with the use of the suction catheters in method B. Relatively high LoDs for semi-volatile compounds in method A are likely due to interaction with surface materials along the longer sample flow path. Several of the compounds listed in Table 4 have shown to be of diagnostic interest: acetone, isoprene, octane, 3-carene, nonanal, dodecane and tetradecane have been linked to VA-LRTI, ${ }^{3,11-13,41-43}$ and isoprene has also been linked to muscle activity ${ }^{44}$ and may thus be altered in mechanically ventilated ICU patients. ARDS has been associated with higher concentrations of octane in exhaled breath (associated with approximately equal LoDs for both methods). ${ }^{45}$ For many of these compounds, method B showed lower LoDs (Table 4). However, the efficacy of both sampling methods is highly compound-dependent and thus will depend on the chemical species under study.

The non-invasive nature of method $\mathrm{A}$ is a significant advantage, allowing it to be implemented in large scale clinical studies (and potentially in clinical practice) more easily. However it should be noted that the creation of a single 'ideal' breath sampling method was not a goal of the present study, as different methodologies may require different sampling approaches. ${ }^{46}$ In our study, we were unable to quantify the potential differences between the ventilators, and as a result of different equipment being used by the different ICUs, the centres were associated with different MDLs. This is an important aspect to consider when conducting multi-centre studies and highlights the importance of a standardized approach to breath sampling both in the critical care unit and across the wider research community.

\section{Author contributions}

PvO, CJ, PD and SF conceived and designed the experiments. PvO, CJ and IW performed the experiments. IW analysed the data. PvO, IW and SF wrote the initial manuscript; WA revised the manuscript in response to peer review. PvO, WA, CJ, JBS, TF, LDB, RG, PD and SF approved the final manuscript.

\section{Conflicts of interest}

The authors declare no conflict of interest.

\section{Acknowledgements}

This study was funded by the NIHR, award number II-LA-021420009, and supported by the NIHR Manchester Clinical Research Facility. IW, PMD, TF and SJF are supported by the NIHR Manchester Biomedical Research Centre. We would like to acknowledge the support from Salford Royal Hospital and their Critical Care for the use of the ventilator circuit equipment and decommissioning and regular servicing, as well as the support of the translational Clinical Science laboratories.

\section{References}

1 B. de Lacy Costello, A. Amann, H. Al-Kateb, C. Flynn, W. Filipiak, T. Khalid, D. Osborne and N. M. Ratcliffe, J. Breath Res., 2014, 8, 014001.

2 A. W. Boots, J. J. B. N. van Berkel, J. W. Dallinga, A. Smolinska, E. F. Wouters and F. J. van Schooten, J. Breath Res., 2012, 6, 027108.

3 L. D. J. Bos, P. J. Sterk and M. J. Schultz, PLoS Pathog., 2013, 9, e1003311.

4 M. P. van der Schee, T. Paff, P. Brinkman, W. M. C. van Aalderen, E. G. Haarman and P. J. Sterk, Chest, 2015, 147, 224.

5 M. Basanta, B. Ibrahim, R. Dockry, D. Douce, M. Morris, D. Singh, A. Woodcock and S. J. Fowler, Respir. Res., 2012, 13, 72 .

6 N. Fens, A. H. Zwinderman, M. P. Van Der Schee, S. B. De Nijs, E. Dijkers, A. C. Roldaan, D. Cheung, E. H. Bel and P. J. Sterk, Am. J. Respir. Crit. Care Med., 2009, 180, 10761082.

7 T. Paff, M. P. van der Schee, J. M. A. Daniels, G. Pals, P. E. Postmus, P. J. Sterk and E. G. Haarman, J. Cystic Fibrosis, 2013, 12, 454-460.

8 M. Bruins, Z. Rahim, A. Bos, W. W. J. van de Sande, H. P. Endtz and A. van Belkum, Tuberculosis, 2013, 93, 232238.

9 P. M. van Oort, P. Povoa, R. Schnabel, P. Dark, A. Artigas, D. Bergmans, T. Felton, L. Coelho, M. J. Schultz, S. J. Fowler and L. D. Bos, J. Breath Res., 2018, 12, 24001.

10 L. D. J. Bos, M. J. Schultz and P. J. Sterk, BMC Pulm. Med., 2014, 14, 72 .

11 S. J. Fowler, M. Basanta-Sanchez, Y. Xu, R. Goodacre and P. M. Dark, Thorax, 2015, 320-325.

12 R. Schnabel, R. Fijten, A. Smolinska, J. Dallinga, M.-L. Boumans, E. Stobberingh, A. Boots, P. Roekaerts, D. Bergmans and F. J. van Schooten, Sci. Rep., 2015, 5, 17179.

13 P. M. P. van Oort, S. De Bruin, H. Weda, H. H. Knobel, M. J. Schultz and L. D. Bos, Int. J. Mol. Sci., 2017, 18, 1-14. 
14 W. Miekisch, J. K. Schubert and G. F. Noeldge-Schomburg, Clin. Chim. Acta, 2004, 347, 25-39.

15 W. Filipiak, R. Beer, A. Sponring, A. Filipiak, C. Ager, A. Schiefecker, S. Lanthaler, R. Helbok, M. Nagl, J. Troppmair and A. Amann, J. Breath Res., 2015, 9, 016004.

16 N. J. W. Rattray, Z. Hamrang, D. K. Trivedi, R. Goodacre and S. J. Fowler, Trends Biotechnol., 2014, 32, 538-548.

17 W. Filipiak, A. Filipiak, C. Ager, H. Wiesenhofer and A. Amann, J. Breath Res., 2012, 6, 027107.

18 S. Ghimenti, T. Lomonaco, F. G. Bellagambi, S. Tabucchi, M. Onor, M. G. Trivella, A. Ceccarini, R. Fuoco and F. Di Francesco, J. Breath Res., 2015, 9, 047110.

19 P. Mochalski, J. King, K. Unterkofler and A. Amann, Analyst, 2013, 138, 1405-1418.

20 M. P. van der Schee, N. Fens, P. Brinkman, L. D. Bos, M. D. Angelo, T. M. Nijsen, R. Raabe, H. H. Knobel, T. J. Vink and P. J. Sterk, J. Breath Res., 2013, 7, 16002.

21 P. Trefz, L. Rösner, D. Hein, J. K. Schubert and W. Miekisch, Anal. Bioanal. Chem., 2013, 405, 3105-3115.

22 D. Biagini, T. Lomonaco, S. Ghimenti, F. G. Bellagambi, M. Onor, M. C. Scali, V. Barletta, M. Marzilli, P. Salvo, M. G. Trivella, R. Fuoco and F. Di Francesco, J. Breath Res., 2017, 11, 047110.

23 I. Horváth, P. J. Barnes, S. Loukides, P. J. Sterk, M. Högman, A. C. Olin, A. Amann, B. Antus, E. Baraldi, A. Bikov, A. W. Boots, L. D. Bos, P. Brinkman, C. Bucca, G. E. Carpagnano, M. Corradi, S. Cristescu, J. C. De Jongste, A. T. Dinh-Xuan, E. Dompeling, N. Fens, S. Fowler, J. M. Hohlfeld, O. Holz, Q. Jöbsis, K. Van De Kant, H. H. Knobel, K. Kostikas, L. Lehtimäki, J. O. Lundberg, P. Montuschi, A. Van Muylem, G. Pennazza, P. Reinhold, F. L. M. Ricciardolo, P. Rosias, M. Santonico, M. P. van der Schee, F. J. van Schooten, A. Spanevello, T. Tonia and T. J. Vink, Eur. Respir. J., 2017, 49, 1600965.

24 L. Bos, M. Schultz and P. Sterk, Respir. Physiol. Neurobiol., 2014, 191, 67-74.

25 M. Basanta, B. Ibrahim, D. Douce, M. Morris, A. Woodcock and S. J. Fowler, J. Breath Res., 2012, 6, 26002.

26 L. W. Sumner, A. Amberg, D. Barrett, M. H. Beale, R. Beger, C. A. Daykin, T. W.-M. Fan, O. Fiehn, R. Goodacre, J. L. Griffin, T. Hankemeier, N. Hardy and J. Harnly, Metabolomics, 2007, 3, 211-221.

27 C. E. Rostad and W. E. Pereira, J. High Resolut. Chromatogr. Chromatogr. Commun., 1986, 9, 328-334.
28 I. Jerkovic, G. Hegic, Z. Marijanovic and D. Bubalo, Molecules, 2010, 15, 2911-2924.

29 B. Tirillini, G. Verdelli, F. Paolocci, P. Ciccioli and M. Frattoni, Phytochemistry, 2000, 55, 983-985.

30 G. Fischer and P. Kusch, LC-GC Int., 1993, 6, 760-763.

31 U. Kotowska, M. Zalikowski and V. Isidorov, Environ. Monit. Assess., 2012, 184, 2893-2907.

32 J. Pino, E. Marquez, C. Quijano and D. Castro, Cienc. Technol. Aliment., 2010, 30, 183-187.

33 J. Weller and M. Wolf, Beitr. Gerichtl. Med., 1989, 47, 525532.

34 F. Khorasheh, M. Gray and M. Selucky, J. Chromatogr., 1989, 481, 1-16.

35 A. Kadri, Z. Zarai, I. Chobba, A. Bekir, N. Gharsallah, M. Damak and R. Gdoura, J. Med. Plants Res., 2011, 5, 6502-6508.

36 D. Helmig, W. Pollock, J. Greenberg and P. Zimmerman, J. Geophys. Res., 1996, 101, 14697-14710.

37 J. Spadone, G. Takeoka and R. Liardon, J. Agric. Food Chem., 1990, 38, 226-233.

38 C. Zhao, Y. Liang, H. Fang and X. Li, J. Chromatogr. A, 2005, 1096, 76-85.

39 S. Kischkel, W. Miekisch, P. Fuchs and J. K. Schubert, Eur. Respir. J., 2012, 40, 706-713.

40 J. Julák, E. Stránská, V. Rosová, H. Geppert, P. Španěl and D. Smith, J. Microbiol. Methods, 2006, 65, 76-86.

41 W. Filipiak, A. Sponring, M. M. Baur, C. Ager, A. Filipiak, H. Wiesenhofer, M. Nagl, J. Troppmair and A. Amann, Microbiology, 2012, 158, 3044-3053.

42 O. Lawal, H. Muhamadali, W. M. Ahmed, I. R. White, T. M. E. Nijsen, R. Goodacre and S. J. Fowler, J. Breath Res., 2018, 12, 26002.

43 P. M. van Oort, P. Brinkman, G. Slingers, G. Koppen, A. Maas, J. J. Roelofs, R. Schnabel, D. C. Bergmans, M. Raes, R. Goodacre, S. J. Fowler, M. J. Schultz and L. D. Bos, Am. J. Physiol.: Lung Cell. Mol. Physiol., 2019, 316, L751-L756.

44 M. Stein, M. Klieber, M. Baumann, K. Unterkofler, G. Teschl, A. Amann, P. Mochalski and J. King, Biochem. Biophys. Res. Commun., 2012, 423, 526-530.

45 L. D. J. Bos, H. Weda, Y. Wang, H. H. Knobel, T. M. E. Nijsen, T. J. Vink, A. H. Zwinderman, P. J. Sterk and M. J. Schultz, Eur. Respir. J., 2014, 44, 188-197.

46 J. D. Beauchamp and J. D. Pleil, J. Breath Res., 2013, 7, 1-3. 